\title{
Efficient practical means in prevention of prematurity
}

\author{
Udo B. Hoyme ${ }^{1 *}$ and Martin Hesse ${ }^{2}$ \\ ${ }^{1}$ Departement OB/GYN, Ilm-Kreis-Kliniken, Arnstadt, Germany \\ ${ }^{2}$ Berufsverband der Frauenaerzte Thuringia, Germany
}

Effective prevention of preterm birth as cause of serious risks for the infant as well as the mother is one of the still unsolved problems in modern medicine. The list of factors for miscarriage, prematurity and stillbirth is lengthy. Many microbial factors may be involved and count for about $80 \%$ in the pathogenesis, e.g. release of proteases and phospholipase A2 from membranes, lysosomes and bacteria as Bacteroides and Prevotella spp. This may result in the synthesis of prostaglandins and lead to preterm contractions. Macrophage activation also increases the likelihood of premature rupture of membranes. Abnormal vaginal flora (AVF) as well as bacterial vaginosis $(\mathrm{BV})$ harbor a significant risk for miscarriage or preterm birth of 1.4 .. 6.9.

In the initial so-called Erfurt prematurity trial, based on a simple screening strategy with intravaginal $\mathrm{pH}$ self-measurements (cut off $\mathrm{pH}$ $>4.5$ ), adequate physician- based medical diagnosis and immediate antimicrobial therapy of genital infection, $0.3 \%$ of the neonates $<32+$ 0 weeks were seen in an intervention group vs. $3.3 \%(\mathrm{p}<0.01, \mathrm{n}=2,722)$ in the control group. In the larger state wide Thuringia campaign 2000 the figures were $0.94 \%$ vs. $1.36 \%(\mathrm{p}<0.01, \mathrm{n}=16,276)$. The rate of newborns $<1000 \mathrm{~g}$ was reduced to $0.38 \%$, the lowest incidence ever seen in any of the German states (Figure 1).

The objective of these trials was to prove the efficacy of vaginal $\mathrm{pH}$ self-screening as a substitute tool for detecting, diagnosing and treating $\mathrm{AVF}$ and $\mathrm{BV}$, however, after discontinuation of the campaign the preterm birth rates mounted in the state to the same level as prior to the program. The results also confirmed the high acceptance by the participating women as subject in their pregnancy in contrast to being object in any traditional exclusively physician-based prenatal care, truly a change of paradigm.

Therefore the regime should be implicated as an indicated step of optimizing and rationalizing the national health care system. However, in two decades of discussion we had to learn that the best way to inhibit progress is to cope with problems by preferring the most complicated policies under persistent renunciation of simple solutions. As long as there are no other alternative safe, simple and cheap methods, do we really have to wait even more years to come for a prospectively randomized double-blinded, almost impracticable study with very likely similar results? Do we have to convince the latest skeptical scientist that there are evidence-based means to reduce the incidence of premature birth, already and just now, by screening for and reducing of infectious morbidity in pregnancy and by the same means that of childbed fever as well?!

Insisting scholastically on nothing but the pure evidence sometimes can hamper innovations and potential benefit. Would a similar caution ever had allowed for instance handwashing according to Semmelweis? That being a 170 years old procedure and never been tested in a scientifically controlled clinical study is free of doubt considered as evidence-based medicine! Nowadays the Semmelweis effect is a metaphor for the reflex-like tendency to reject new evidence or new knowledge because it contradicts established norms, beliefs or paradigms [1].

Prevention of preterm birth by an in part selfcare regime should be implicated as a necessary step for optimizing and rationalizing the health care system [2]. The chance to reduce the extremely costly complications associated with preterm birth with minimal expenses comes with the fact that the unmeasurable strain on all parties involved can be reduced in a beneficial way. Can we as physicians, health care providers and politicians ignore these encouraging aspects? Why do we fail to transfer our essential, evidence based knowledge into a worldwide practical strategy? Why do most "experts" accept that an established known risk leads and proceeds to an advanced stage with irreversible changes? Would it not be better to prevent these late stages by earlier use of simple measures?

Dealing with the problem prematurity we have to accept that "evidence based medicine is the conscientious, explicit, and judicious use of current best evidence in making decisions about the care of individual patients" [3]. According to the recent literature, we have the potential means for successfully treating women with threatening premature birth in about $5 \%$ of cases (GAPPS, 2015). The remaining 95\% at risk need help, now! As long as we do not have alternative safe, simple and cheap methods, intravaginal $\mathrm{pH}$-measurement is the best option to detect women at risk and in need for specific diagnostic assessment followed by efficient medical treatment, e.g. lactobacilli, e.g. in case of BV preferably by clindamycin before week $23[4,5]$.

Good news for at least 18000 pregnant women annually: The Government of our State of Thuringia has decided in 2016 to reestablish a pH selfcare screening program similar to that of the year 2000 (Figure 2 ). Beginning at zero almost one year after initiation $>85 \%$ of pregnant women in the state have their vaginal $\mathrm{pH}$ measured in November 2017 (Figure 3)! First pregnancy outcome parameters will be available by mid of 2018.

Correspondence to: Udo B. Hoyme, Ilm-Kreis-Kliniken, Arnstadt-Ilmenau gGmbH, Klinik für Frauenheilkunde und, Geburtshilfe Bärwinkelstraße 33, 99310 Arnstadt, Germany, Tel: (+49) 3628 919-329, Fax: (+49) 3628 919-319, E-mail: Udo.Hoyme@ilm-kreis-kliniken.de

Key words: screening by $\mathrm{pH}$ intravaginal self-measurement, effective prevention, practical / political means

Received: December 05, 2017; Accepted: December 26, 2017; Published: December 29, 2017 


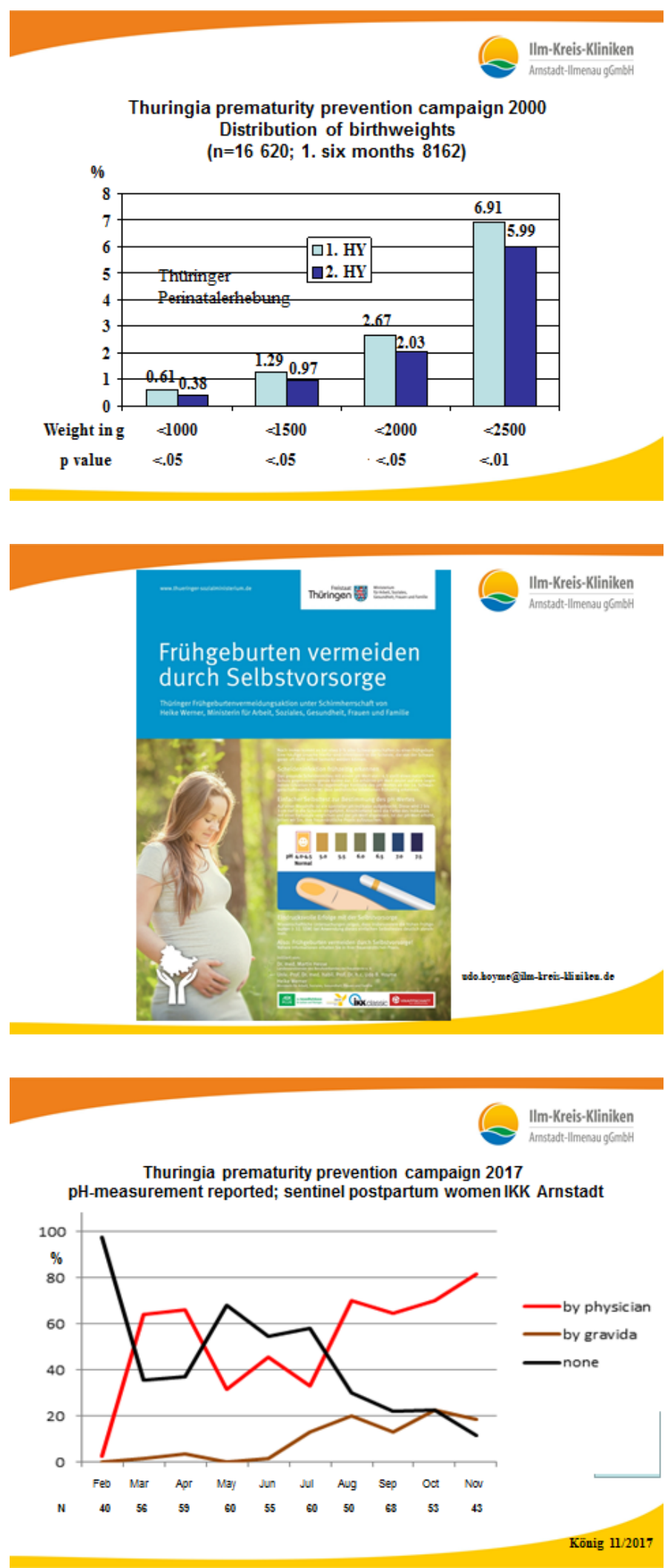

\section{References}

1. Robert Anton Wilson (2017) Wikipedia.

2. Hoyme UB, Saling E (2004) Efficient prematurity prevention is possible by $\mathrm{pH}$-selfmeasurement and immediate therapy of threatening ascending infection. Eur J Obstetr Gynecol Reprod Biol 115: 148-153. [Crossref]

3. Sackett DL, Rosenberg WM, Gray JA, Haynes RB, Richardson WS (1996) Evidence based medicine: what it is and what it isn't. BMJ 312: 71-72. [Crossref]

4. Gravett MG (2015) Preventing preterm birth: A framework towards a global agenda. Presented at IDSOG meeting August 6-8, 2015, Portland.

5. Lamont RF, Nhan-Chang CL, Sobel JD, Workowski K, Conde-Agudelo A, et al. (2011) Treatment of abnormal vaginal flora in early pregnancy with clindamycin for the prevention of spontaneous preterm birth: a systematic review and metaanalysis. $\mathrm{Am} \mathrm{J}$ Obstet Gynecol 205: 177-190. [Crossref]

Copyright: (C2017 Hoyme UB. This is an open-access article distributed under the terms of the Creative Commons Attribution License, which permits unrestricted use, distribution, and reproduction in any medium, provided the original author and source are credited. 